\title{
Content of Polycyclic Aromatic Hydrocarbons (PAHs) and Other Compounds in Autothermal Thermophilic Aerobic Digestion (ATAD) Leachates-The Issue of Returned Leachates ${ }^{+}$
}

\author{
Dariusz Boruszko * and Ada Wojciula \\ Faculty of Civil Engineering and Environmental Sciences, Bialystok University of Technology, \\ 15-351 Białystok, Poland; a.wojciula@doktoranci.pb.edu.pl \\ * Correspondence: d.boruszko@pb.edu.pl \\ + Presented at the 9th Innovations-Sustainability-Modernity-Openness Conference (ISMO'20), Bialystok, \\ Poland, 20-21 May 2020.
}

Published: 13 August 2020

\begin{abstract}
Sewage sludge is a by-product of the municipal wastewater treatment process. The amount of sewage sludge generated in treatment plants in Poland and other European countries is constantly growing. Due to the growing environmental awareness, legal requirements are being established that require the appropriate treatment of sludge before it can be used for natural purposes. Therefore, operators are looking for the best solutions to ensure proper sewage sludge preparation. More and more ATAD (auto-thermophilic sewage sludge stabilization) installations are being built in Poland, which allow for simultaneous stabilization and hygienization of sludge. However, this process contributes to the formation of leachate, which is discharged into the biological reactors of municipal sewage treatment plants. The leachate after the ATAD process has a complex organic substance and is characterized by large loads of total nitrogen and total phosphorus. Biological wastewater treatment processes can be ineffective for such specific pollutants returned in ATAD leachate. Thus far, no research has been undertaken to analyze the problem presented.
\end{abstract}

Keywords: Aerobic Digestion of Sewage Sludge (ATAD), sewage sludge; Polycyclic Aromatic Hydrocarbons (PAHs); returned loads; leachates

\section{Introduction}

In Poland, in the years 2000 to 2015, the amount of municipal sewage sludge produced was constantly increasing. Since 2015, its amount has remained at a similarly high level.

In 2018, about 580,000 tons of dry mass of sludge from municipal sewage treatment plants were generated in Poland [1]. Sewage sludge directly after the treatment process is considered waste and, according to the Waste Act of 14 December 2012, waste can be disposed of only when it cannot be reused [2]. Therefore, in Poland, a large amount of sewage sludge goes to landfills every year [1]. In order to reuse the sludge, processes such as stabilization and hygienization are used. The ATAD process, i.e., auto-thermal thermophilic stabilization of sewage sludge, allows the abovementioned processes to be carried out by means of one installation, which occupies a small area. The owners of sewage treatment plants more and more often appreciate this technology also due to the low emission of harmful gases into the atmosphere [3]. The reactors are fully encapsulated and additionally, devices for removing gaseous pollutants are used. Therefore, ATAD installations are more and more 
often started up in Poland. On the one hand, this method enables quite efficient preparation for the reuse of sludge and, on the other hand, it poses a certain danger due to the leachate being produced [4].

The first FUCHS ATAD plant started up in 1977 and is still in operation. More than 80 ATAD plants followed. There are 11 ATAD installations in Poland on municipal sewage treatment plants, seven of which are located in the north-eastern part of the country. The treatment plant in Olecko in 2018 produced one ton D.M. of sludge, in Wysokie Mazowieckie 60 tons D.M., in Dąbrowa Białostocka 86 tons D.M., in Hajnówka 129 tons D.M., in Pisz 166 tons D.M. and in Kętrzyn 229 tons D.M. [5]. Treatment plants using ATAD technology from another region of Poland are located in Lubań Śląski, Oława, Milicz and Ruda Bugaj. The process of autothermal thermophilic stabilization of sewage sludge is recommended for treatment plants whose capacity does not exceed 20,000 $\mathrm{m}^{3} / \mathrm{d}$ [6].

The consequence of sewage sludge treatment using the ATAD method is the formation of leachate. They are usually formed in two processes. Some leachate is formed on presses or centrifuges, responsible for sludge dewatering. The second process generating leachate is a water scrubber, in which the air from the ATAD process is treated. The activity consists in flushing out pollutants from the scrubber most often with treated sewage $[7,8]$.

The problem is that the leachate is discharged into the biological reactors of the sewage treatment plant. They are characterized by large loads and contain a complex organic substance, different from the one that flows in municipal sewage. The effluents contain complex organic compounds, including PAHs. When combined with municipal wastewater they can cause changes in the biological system and polycyclic aromatic hydrocarbons are biodegradable. The processes with biological treatment with the activated sludge method are mainly used in municipal sewage treatment plants [9]. A significant problem may be the too low efficiency of treatment of the leachate from ATAD with this method. In Poland and Europe, this issue has not yet been properly recognized.

The return of sewage sludge treatment leachate may reduce the efficiency of sewage treatment plants [10]. The processes used in municipal sewage treatment plants are adapted to reduce nitrogen and phosphorus, as required by legal regulations. If the operators decided to build a pre-treatment plant for leachate from dehydrated sludge, better quality leachate would go to sewage treatment plants, and this would positively affect the entire wastewater treatment process. Operators usually do not decide to build such pretreatment plants because they are not required to control PAHs and heavy metals in recycled leachate. Therefore, they are not aware of the problem. Particularly unfavorable may be the return of leachate after autothermal thermophilic stabilization of sewage sludge.

The main objective of the study was to assess the quality of leachate from the ATSO method, mainly the organic matter content and PAH content and the share of their individual groups. The conducted tests allow the determination of the degree of leachate contamination with hardly biodegradable organic compounds after the ATSO process. Moreover, the results make it possible to compare the content of tested compounds in leachates obtained after stabilization with traditional methods and with reference to the ATAD method.

\section{Materials and Methods}

Tests were carried out on ATSO leachate from six wastewater treatment plants in north-eastern Poland (Dąbrowa Białostocka, Olecko, Pisz, Giżycko, Wysokie Mazowieckie, Hajnówka). The content of 16 polycyclic aromatic hydrocarbons were determined: naphthalene, acenaphthylene, acenaphthene, fluorine, phenanthrene, anthracene, fluoranthene, pyrene, benzo(a)anthracene, chrysene, benzo(b)fluoranthene, benzo(k)fluoranthene, benzo(a)pyrene, indeno(1,2,3-cd)pyrene, dibenzo(a,h)anthracene, benzo(g,h,i)perylene. Moreover, total nitrogen, total phosphorus, inorganic carbon, total organic carbon and 9 organic acids (acetic, propionic, isobutyric, butyric, isovalerian, valerian, iso-caprylic, hexane and heptane) were determined.

Total Nitrogen, phosphorus, TOC and TC were determined by using standard methods [11].

The study of polycyclic aromatic hydrocarbons PAHs contents in sewage sludge used gas chromatography coupled with mass spectrometry detection. In purified and concentrated extracts from sewage sludge, 16 PAHs were identified (according to US EPA): naphthalene (NAPH), acenaphthylene (ACY), acenaphthene (ACE), fluorene (FLU), phenanthrene (PHE), anthracene 
(ANT), fluoranthene (FLA), pyrene (PYR), benzo[a]anthracene (B[a]ANT), chrysene (CHR), benzo[b]fluoranthene (B[b]FLA), benzo[k]fluoranthene (B[k]FLA), benzo[a]pyrene (B[a]PYR), dibenzo[a,h]anthracene (D[a,h]ANT), indeno[1,2,3-c,d]pyrene (Ind[1,2,3-c,d]P), benzo[g,h,i]perylene $(\mathrm{B}[\mathrm{g}, \mathrm{h}, \mathrm{i}] \mathrm{PER})$, as well as their sum [11].

\section{Results and Discussion}

The highest amount of organic acids occurred in leachate from the treatment plant in Wysokie Mazowieckie $(6508.77 \mathrm{mg} / \mathrm{L})$ and Giżycko $(2435.24 \mathrm{mg} / \mathrm{L})$. All nine acids were found in these leachates. In the samples from the remaining treatment plants, only acetic or propionic acid was found, and their total amount ranged from 0.37 to $5.07 \mathrm{mg} / \mathrm{L}$. The highest content of inorganic carbon was found in the sample from Hajnówka, $7.31 \mathrm{mg} / \mathrm{L}$, and the lowest in the leachate from Pisz $(0.73$ $\mathrm{mg} / \mathrm{L}$ ). In the case of total organic carbon, the value ranged from $42 \mathrm{mg} / \mathrm{L}$ in the sample from Dabrowa Bialostocka to $2720 \mathrm{mg} / \mathrm{L}$ in the sample from Gizycko. Total nitrogen occurred in the smallest amount in the leachate from Dabrowa Bialostocka $(227 \mathrm{mg} / \mathrm{L})$. Overall, $87 \%$ more nitrogen was found in the leachate from the treatment plant in Giżycko $(1740 \mathrm{mg} / \mathrm{L})$. Polycyclic aromatic hydrocarbons occurred in each sample. Their sum ranged from 2.89 to $56.65 \mu \mathrm{g} / \mathrm{L}$. The least PAHs compounds were found in the leachate from the treatment plant in Olecko and the most in Hajnówka. Large differences occurred in the case of acenaphthylene, as its amount ranged from 0.015 to $11.45 \mu \mathrm{g} / \mathrm{L}$. The amount of benzo(a)fluoranthene also differed (from 0.195 to $14.98 \mu \mathrm{g} / \mathrm{L}$ ). The content of indeno(1,2,3cd)pyrene in the sample from Wysokie Mazowieckie was about 20 times higher than in other samples. The content of total 16 PAHs in the leachate depended on the type of sewage sludge and the highest was found in the treatment plant in Hajnówka. The share of PAHs groups depending on the number of rings in the leachate was varied. The group of five- and six-ring hydrocarbons dominated in the leachate and the lowest number of two- and three-ring hydrocarbons was found. The obtained research results will allow comparison of the obtained values with the content of compounds in the leachate obtained after stabilization by traditional methods.

The hydrophobic properties and ease of absorption on particles of polycyclic aromatic hydrocarbons determine that PAHs are not readily biodegradable. This is especially true for hydrocarbons with more rings. In anaerobic conditions, PAHs are broken down even 100 times slower [12]. The intensity of transformation of polycyclic aromatic hydrocarbons also depends on other physical properties, chemical properties, external environmental influences and composition of the microflora. It is important to know what physicochemical and biological conditions should be created in order to be able to biodegrade polycyclic aromatic hydrocarbons. This can be particularly difficult because PAHs have a clear resistance to degradation and are classified as xenobiotics. AHChigh molecular weight (HMW) compounds, i.e., having four or more rings, were found in leachate from ATSO. This is due to the fact that such compounds have a high molecular weight, and their halflife may be even over 1800 years [13,14]. Pyrene, benzo (a) pyrene, acenaphthene, acenaphthylene, benzo (b) fluoranthene, benzo ( $k$ ) fluoranthene, benzo $(g, h, i)$ perylene, anthracene, benzo (a) anthracene, chrysene, dibenzo $(\mathrm{a}, \mathrm{h})$ anthracene, fluoranthene, fluoren, phenanthrene are the most carcinogenic and mutagenic, and insufficient, insufficient sewage treatment causes these compounds to enter the environment together with treated sewage. The conducted tests proved that leachates from ATSO contain the most toxic, dangerous PAH compounds. Polycyclic aromatic hydrocarbons, without the participation of microflora, are decomposed in the processes of sorption, photodegradation, chemical oxidation, or as a result of additive or substitution reactions with other chemical compounds. The gravity process, which causes settling of suspended solids in sewage, allows only for partial elimination of PAH compounds from sewage. Photodegradation has a greater impact on PAHs, and decomposition takes place under the influence of UV ultraviolet light [15].

\section{Conclusions}

The main objective of the study was to assess the quality of leachate from the ATSO method, mainly the organic matter content and PAH content and the share of their individual groups. The conducted tests allow the determination of the degree of leachate contamination with hardly 
biodegradable organic compounds after the ATSO process. Moreover, the results make it possible to compare the content of tested compounds in leachates obtained after stabilization with traditional methods and with reference to the ATAD method.

Author Contributions: D.B. conceived and designed the experiments and analyzed the data. A.W. performed the experiments and contributed materials. All authors have read and agreed to the published version of the manuscript.

Funding: This research received no external funding.

Acknowledgments: This research was funded by the Ministry of Science and Higher Education within the framework of the work No. S/WBiIŚ/3/2014.

Conflicts of Interest: The authors declare no conflict of interest.

\section{References and Note}

1. Central Statistical Office. Environmental Protection 2019, Warszawa; Central Statistical Office: New Delhi, India, 2019; p. 70. (In Polish)

2. Regulation of the Minister of Environment from 14th of December 2012 on Waste (Dz.U. 2013 pos. 21); Section II, Chapter I, Article 17, Page 7. (In Polish)

3. Augustin, O.; Bartkowska, I.; Dzienis, L. Efficiency of wastewater sludge disinfection by autoheated thermophilic aerobic digestion (ATAD). In Proceedings of the IWA Specialist Conference: Moving Forward: Wasterwater Biosolids Sustainability: Technical, Managerial and Public Synergy: Conference Proceedings, Moncton, NB, Canada, 24-27 June 2007; pp. 1037-1043.

4. Bartkowska, I. Autothermal Thermophilic Stabilization of Sewage Sludge; Seidel-Przywecki Publishing House: Józefosław, Poland, 2017. (In Polish)

5. Available online: https://bdl.stat.gov.pl/BDL/start (accessed on 10 February 2020).

6. Bartkowska, I. Evaluation of selected technological parameters of the autothermal aerobic sludge stabilisation (ATAD) process on the example of a sewage treatment plant in Lubań. Ecol. Eng. 2011, 25, 719. (In Polish)

7. Hepner, S.; Striebig, B.; Regan, R.; Giani, R. Odor Generation and Control from the Autothermal Thermophilic Aerobic Digestion (ATAD) Process; Water Environment Federation: Alexandria, VA, USA, 2002; pp. 598-607.

8. Bartkowska, I.; Dzienis, L.; Wawrentowicz, D. Efficiency of operation of the sewage treatment plant in Hajnówka and a proposal for its modernisation. Ecol. Eng. 2011, 24, 226-235. (In Polish)

9. Miksch, K.; Sikora, J. Sewage Biotechnology; PWN Scientific Publishing House: Warsaw, Poland, 2010. (In Polish)

10. Gajewska, M.; Obarska-Pempkowiak, H. The effect of sewage sludge dewatering on sewage treatment plant operation. Chem. Ind. 2008, 87, 448-451. (In Polish)

11. Standard Methods for the Examination of Water and Wastewater, 21st ed.; American Public Health Association/American Water Works Association/Water Environment Federation: Washington DC, USA, 2005.

12. Włodarczyk-Makuła, M.; Wierzbicka, M. Warunku biodegradacji WWA w środowisku wodnym. LAB Lab. Apar. Bad. 2013, 18, 28-32.

13. Gateuille, D.; Evrard, O.; Lefevre, I.; Moreau-Guigon, E.; Alliot, F.; Chevreuil, M.; Mouchel, J.M. Mass balance and decontamination times of Polycyclic Aromatic Hydrocarbons in rural nested catchments of an early industrialized region (Seine River basin, France). Sci. Total Environ. 2014, 470-471, 608-617.

14. Lamichhane, S.; Krishna, K.C.; Sarukkalige, R. Polycyclic aromatic hydrocarbons (PAHs) removal by sorption: A review. Chemosphere 2016, 148, 336-353.

15. Forsgren, A.J. Wastewater Treatment: Occurrence and Fate of Polycyclic Aromatic Hydrocarbons (PAHs); CRC Press: Boca Raton, FL, USA, 2015; ISBN 9781482243178.

(C) 2020 by the authors. Licensee MDPI, Basel, Switzerland. This article is an open access article distributed under the terms and conditions of the Creative Commons Attribution (CC BY) license (http://creativecommons.org/licenses/by/4.0/). 